\title{
Abstract ID: 819
}

t-SNE applied to discriminate healthy individuals from those with Parkinson's disease executing motor tasks detected by non-contact capacitive sensors

Fábio Henrique M. Oliveira1,2 - oliveirafhm@gmail.com Adriano O. Andrade1 - adriano@ufu.br Thaíla Ferreira Zaruz1 - tzaruz@gmail.com Marcus Fraga Vieira ${ }^{3}$ - marcus@ufg.br 
World Congress on Medical Physics

$\&$ Biomedical Engineering

June 3-8, 2018, Prague, Cżech Republic, www.iupesm2018.org

\section{Introduction symptoms}

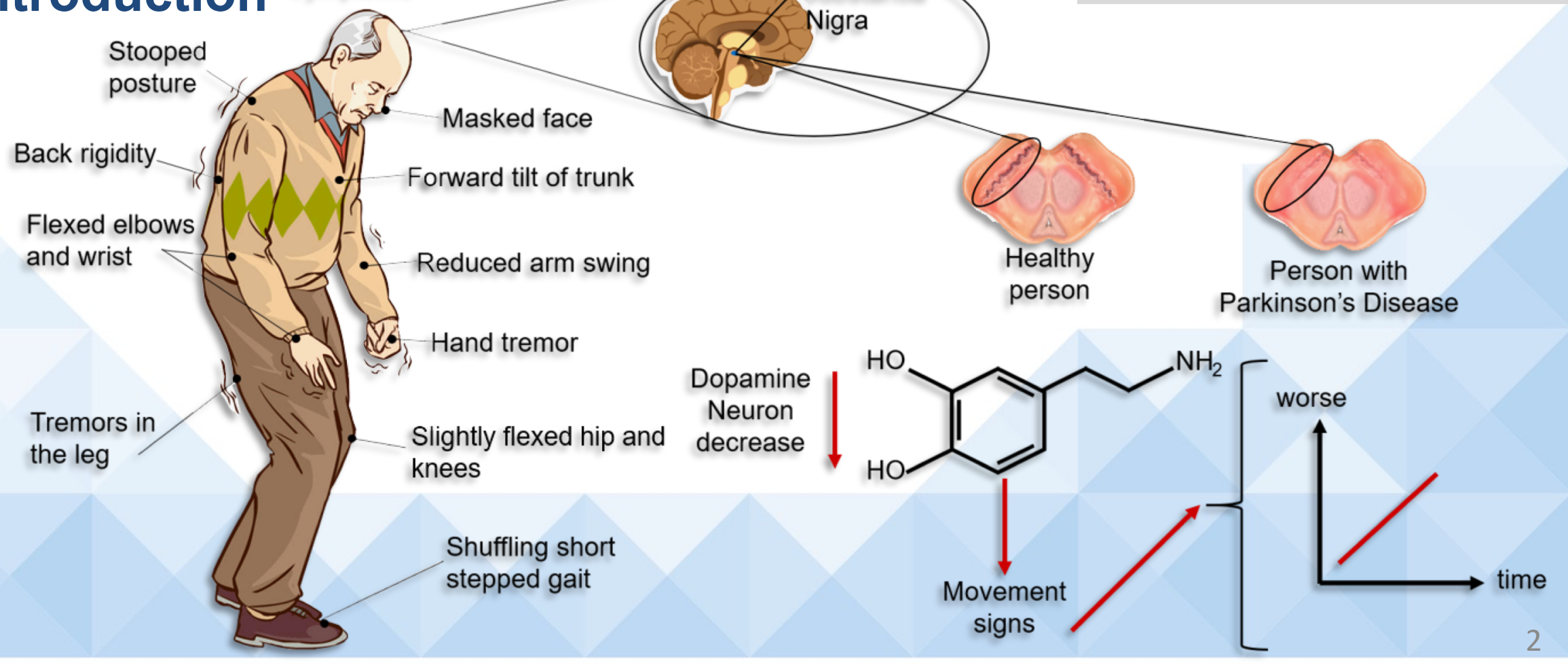


World Congress on Medical Physics

\& Biomedical Engineering

June 3-8, 2018, Prague, Cżech Republic, www.iupesm2018.org

\section{Introduction}

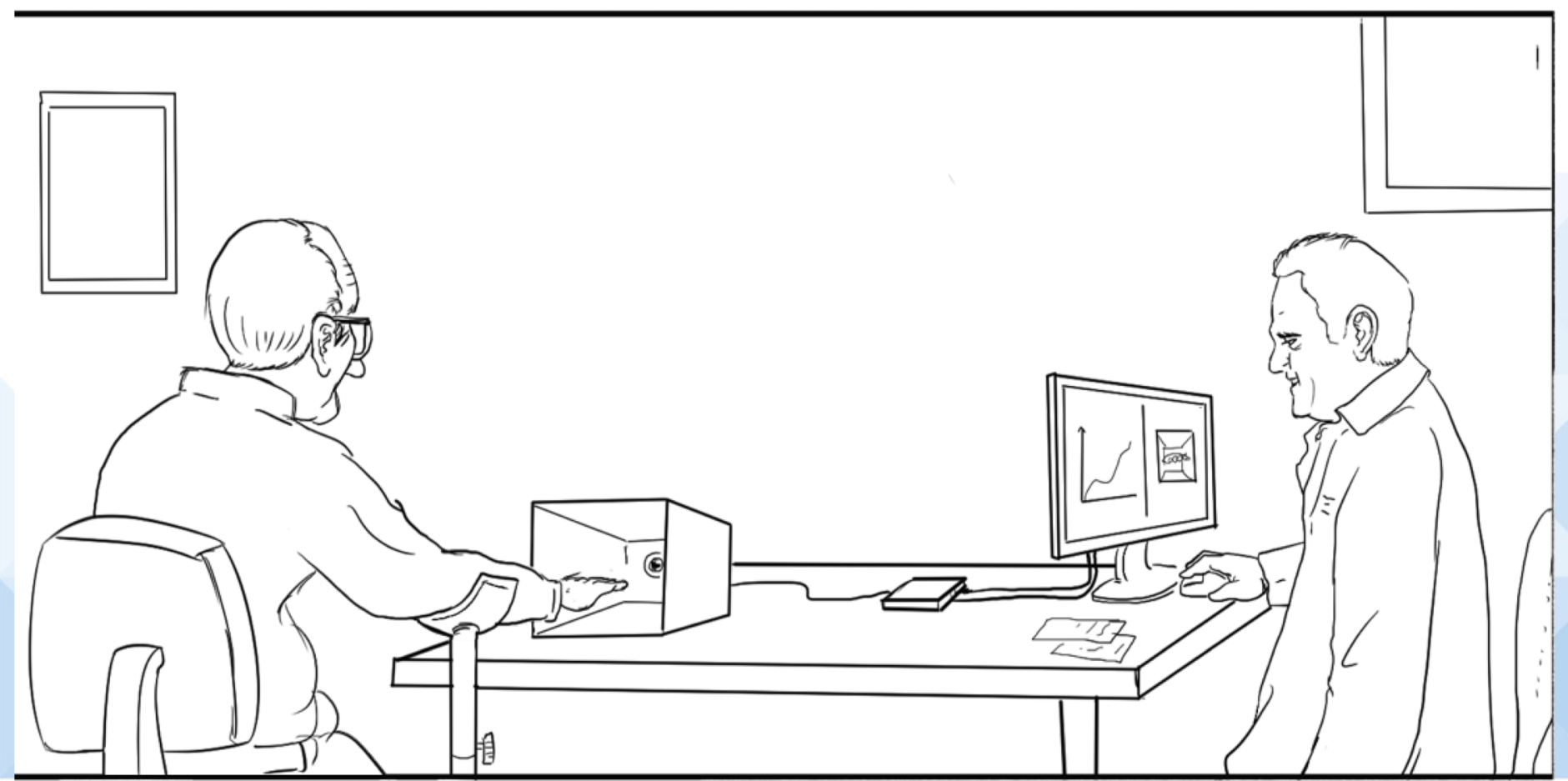


World Congress on Medical Physics

$\&$ Biomedical Engineering

June 3-8, 2018, Prague, Cżech Republic, www.iupesm2018.org

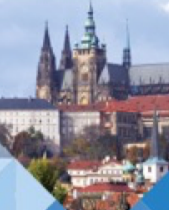

\section{Introduction}

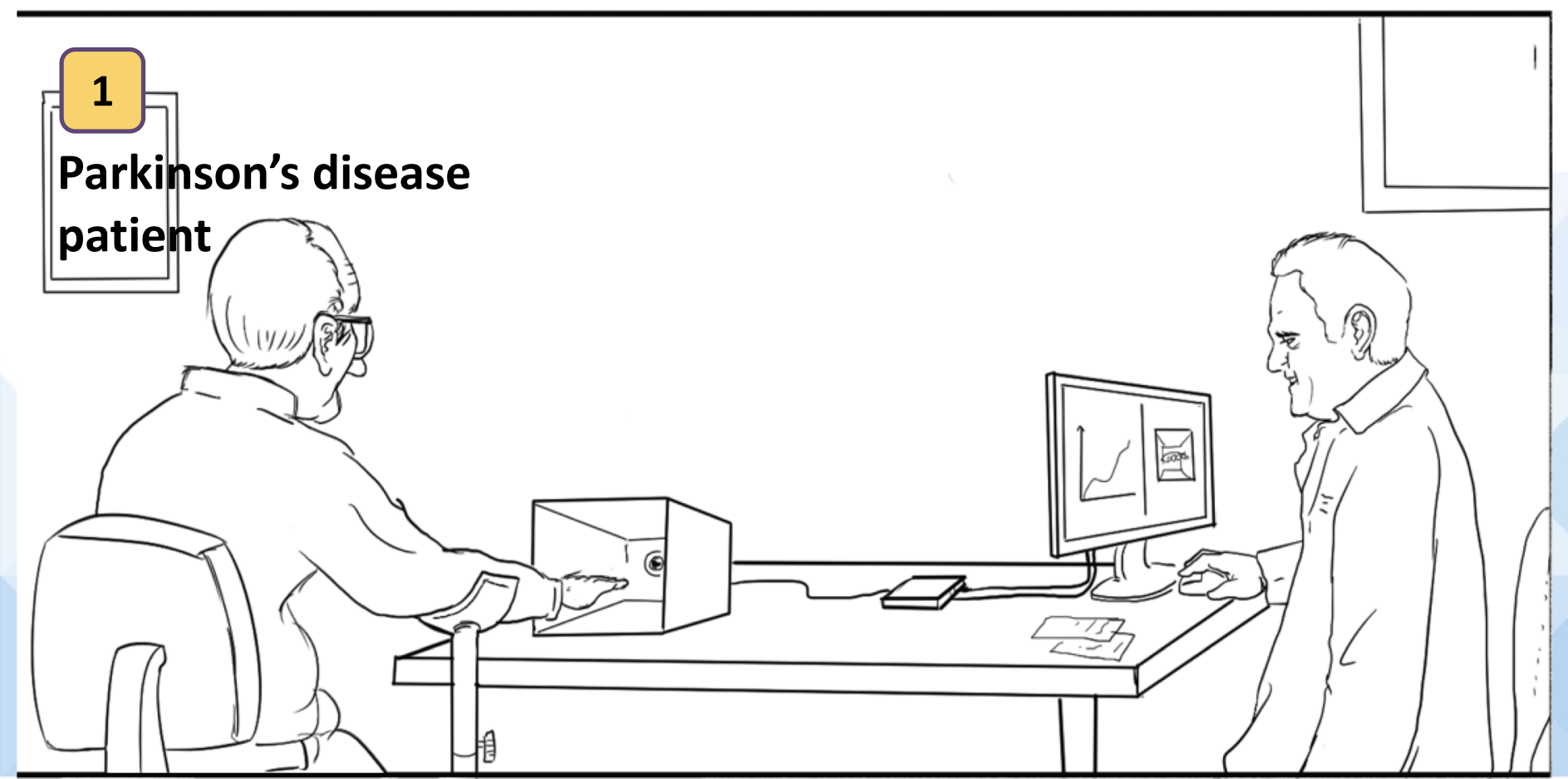


World Congress on Medical Physics

$\&$ Biomedical Engineering

\section{Introduction}

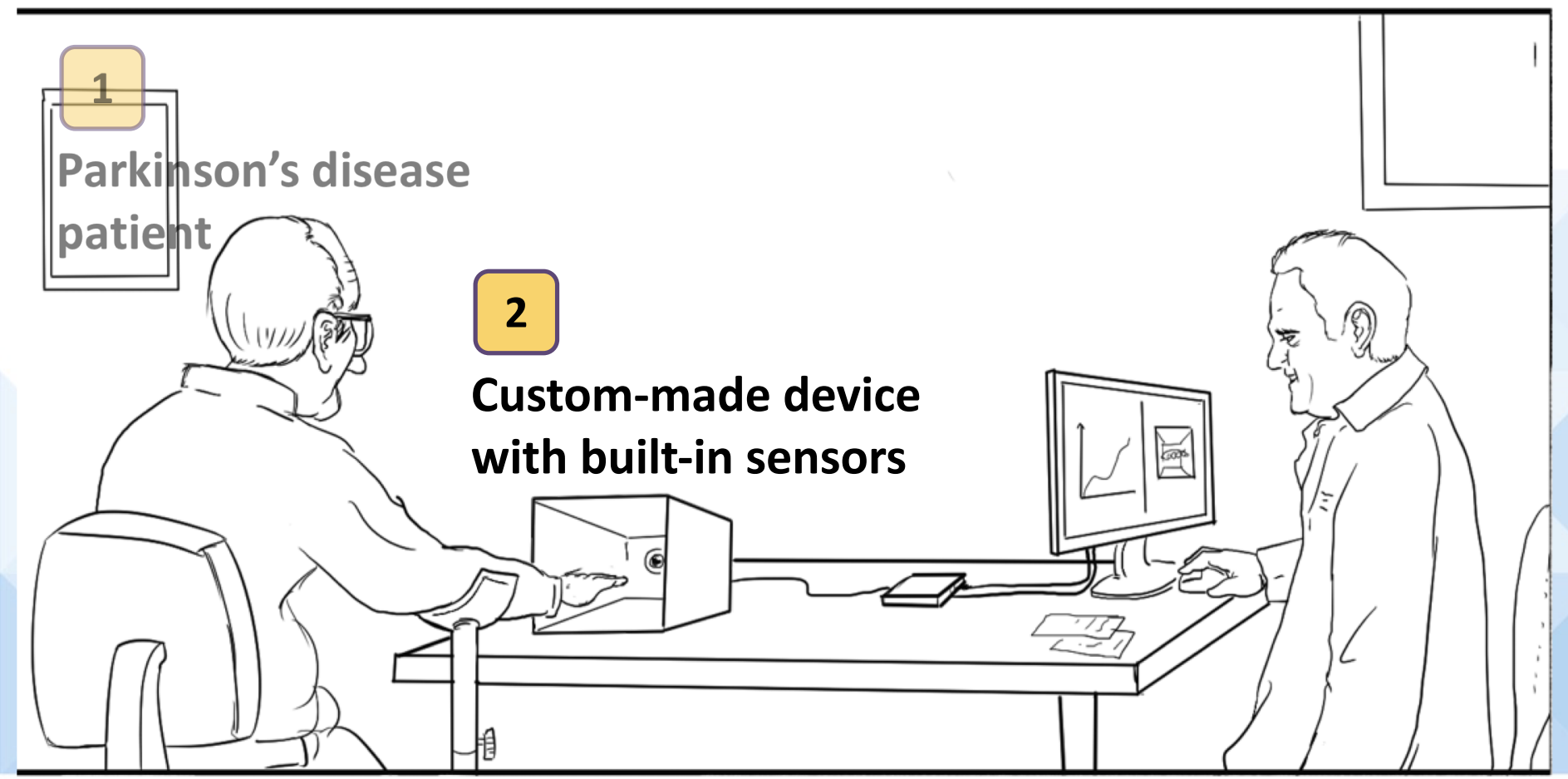


World Congress on Medical Physics

\& Biomedical Engineering

\section{Introduction}

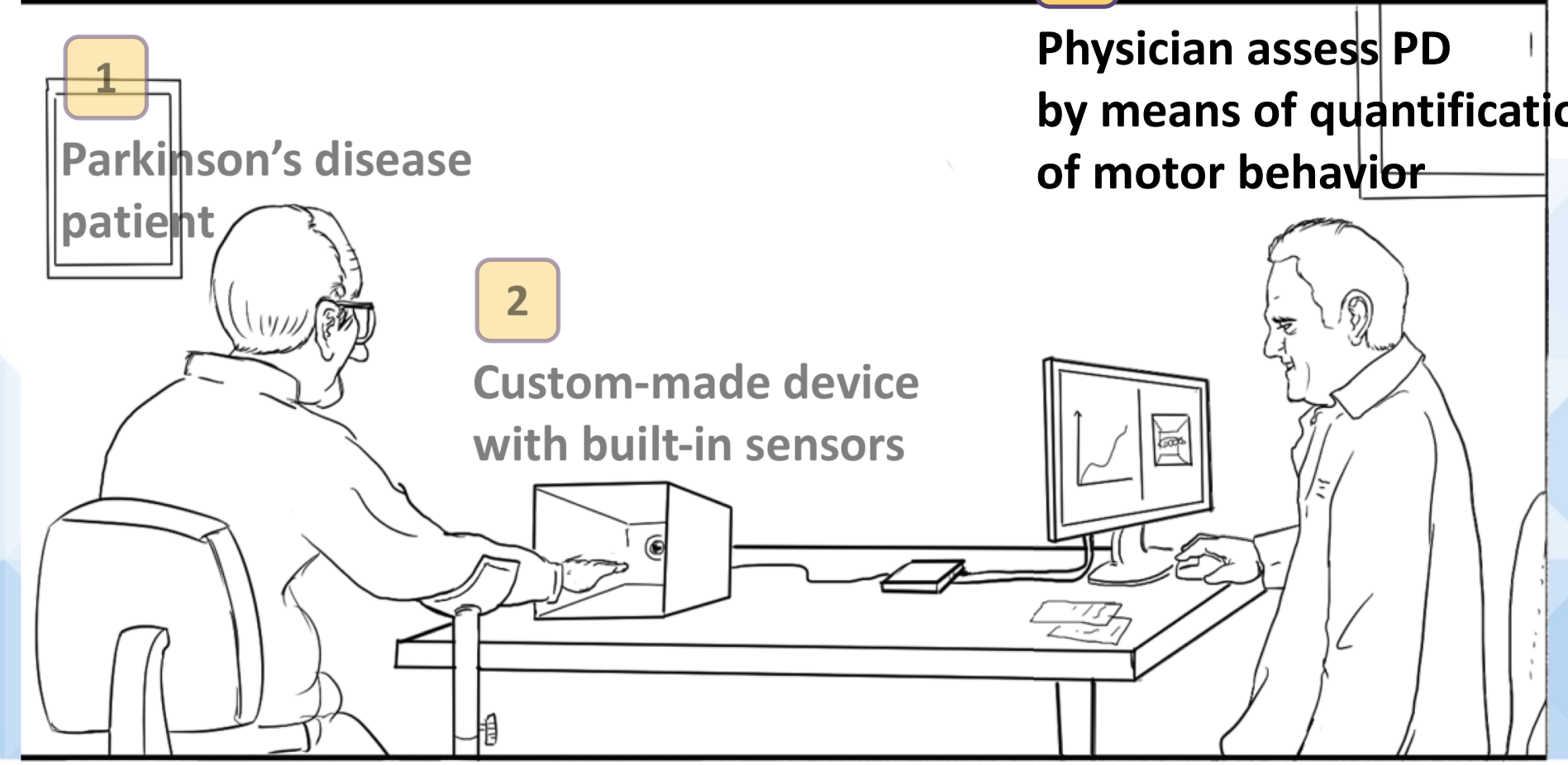


World Congress on Medical Physics

\& Biomedical Engineering

June 3-8, 2018, Prague, Cżech Republic, www.iupesm2018.org

\section{Introduction}

Sensors

Parkinson's Disease

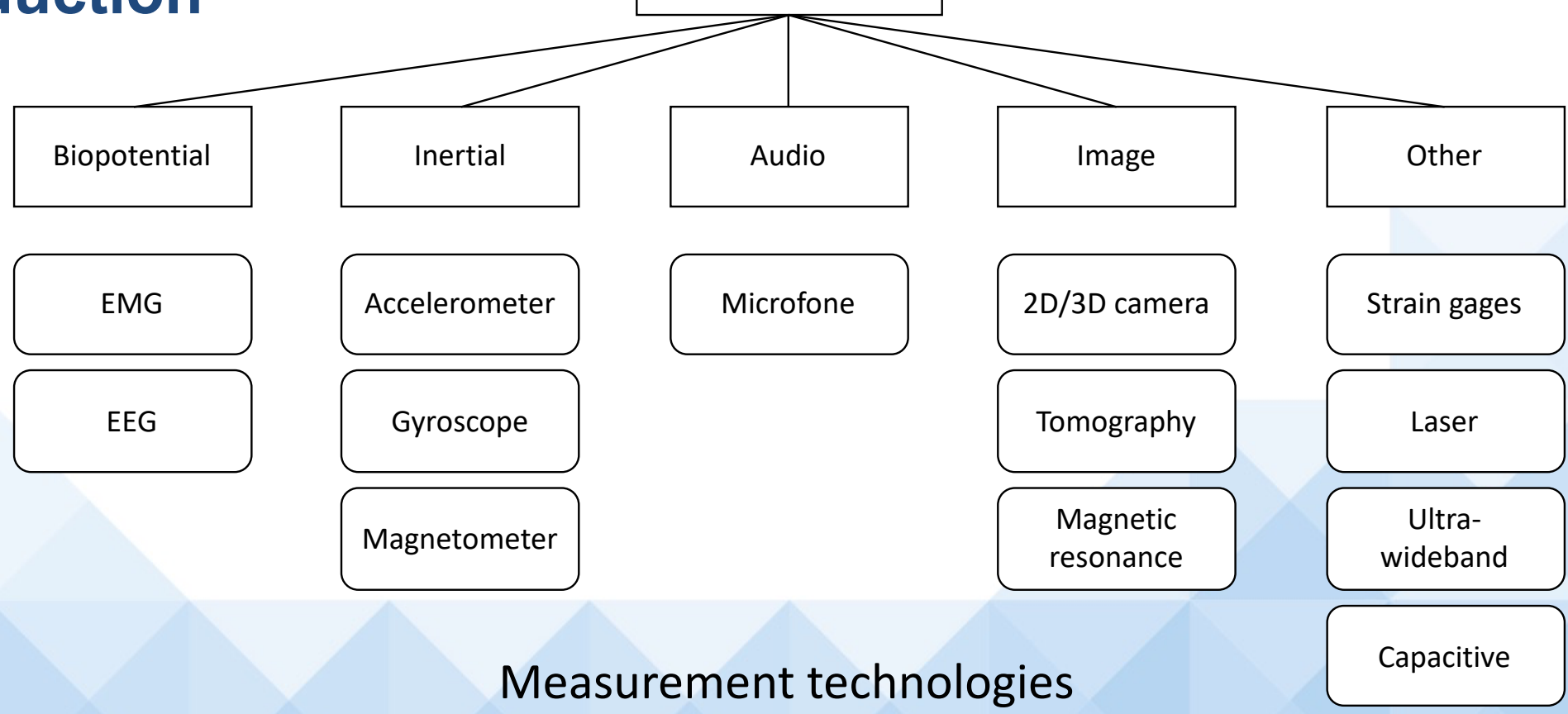

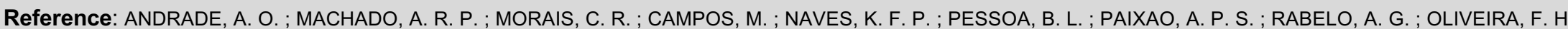

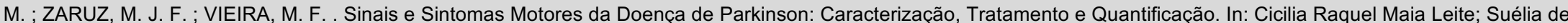

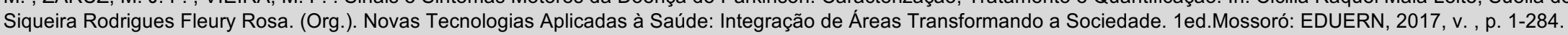


World Congress on Medical Physics

$\&$ Biomedical Engineering

June 3-8, 2018, Prague, Cżech Republic, www.iupesm2018.org

\section{Methods}

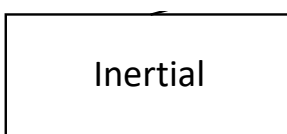

Gyroscope
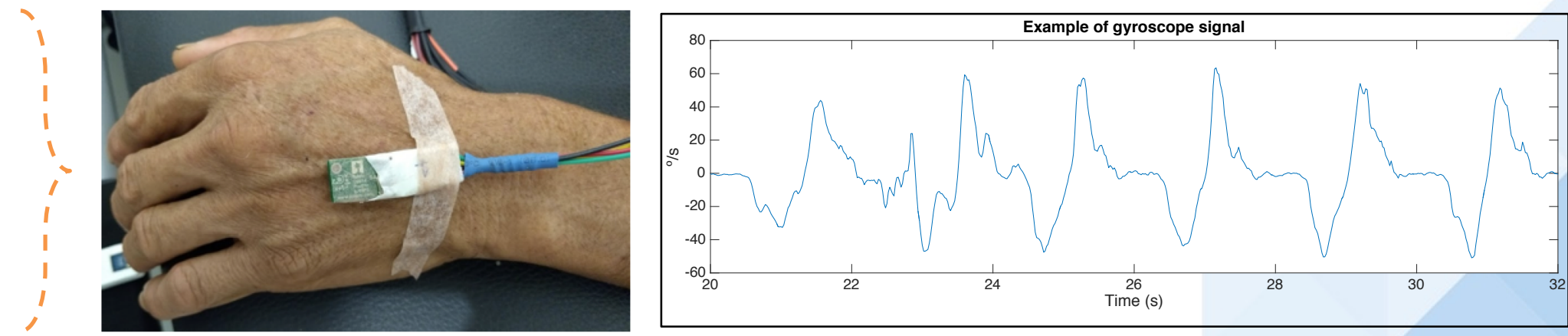

Other

Capacitive
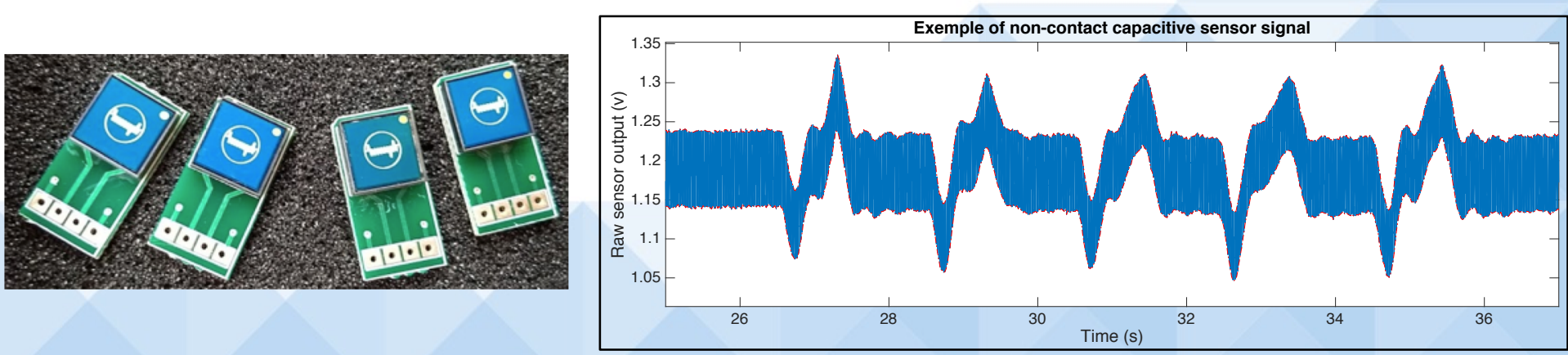
World Congress on Medical Physics

$\&$ Biomedical Engineering

June 3-8, 2018, Prague, Cżech Republic, www.iupesm2018.org

\section{Methods}

\section{Experimental setup}
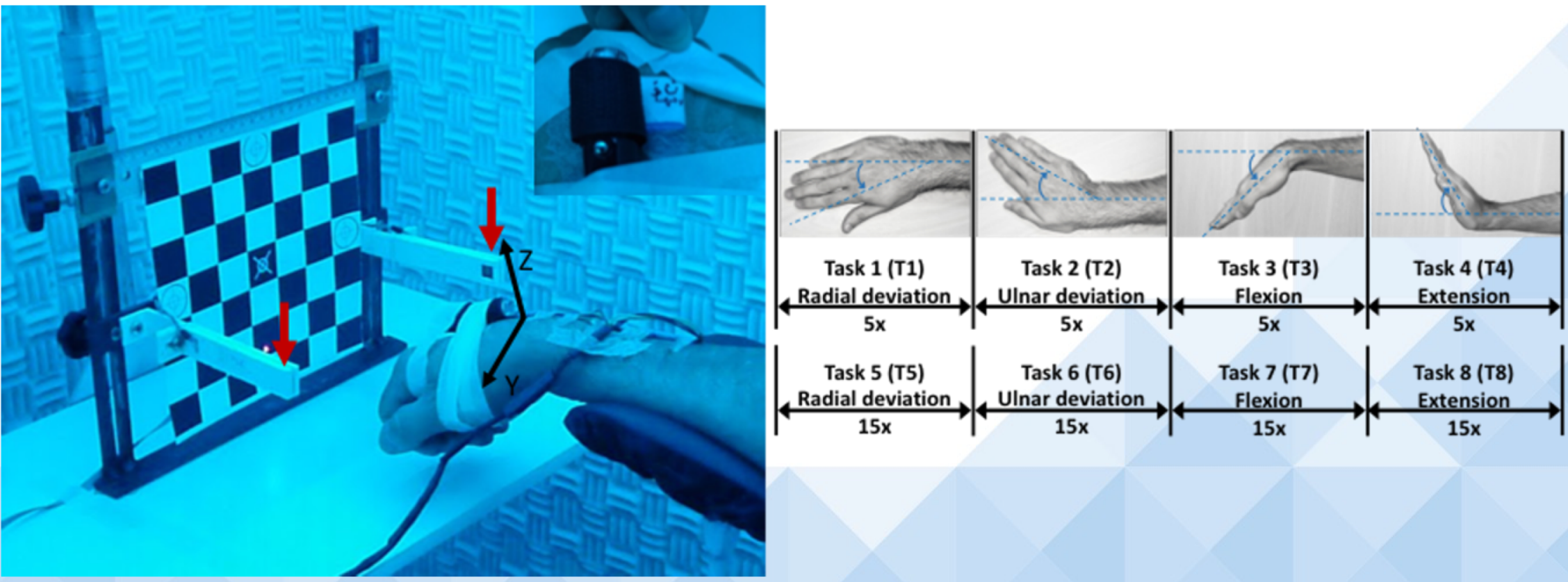

Ethics committee approval: 65165416.4.0000.5152 
World Congress on Medical Physics

\& Biomedical Engineering

\section{Methods}

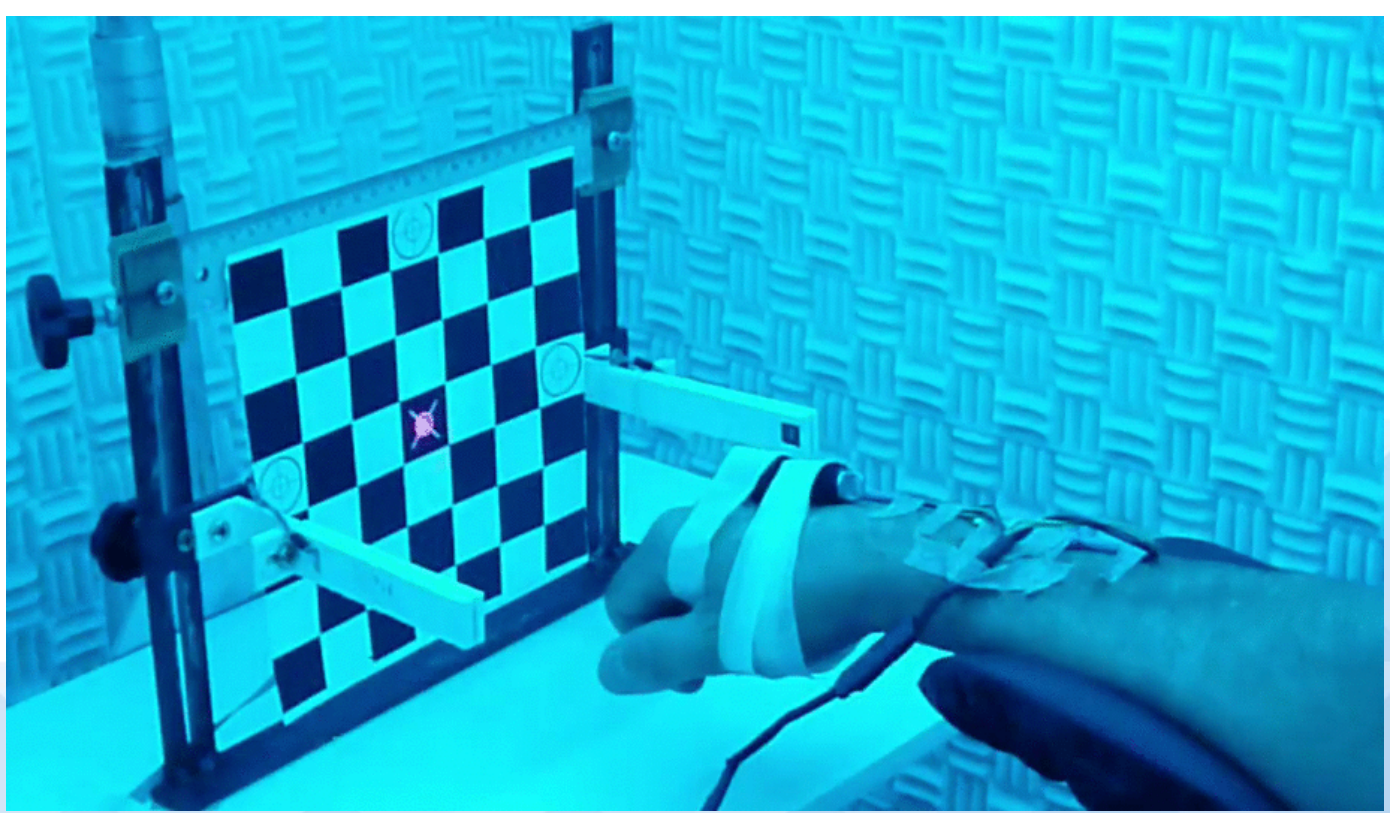

Sequence of images of an experiment trial 
World Congress on Medical Physics

\& Biomedical Engineering

June 3-8, 2018, Prague, Cżech Republic, www.iupesm2018.org

\section{Results}

a
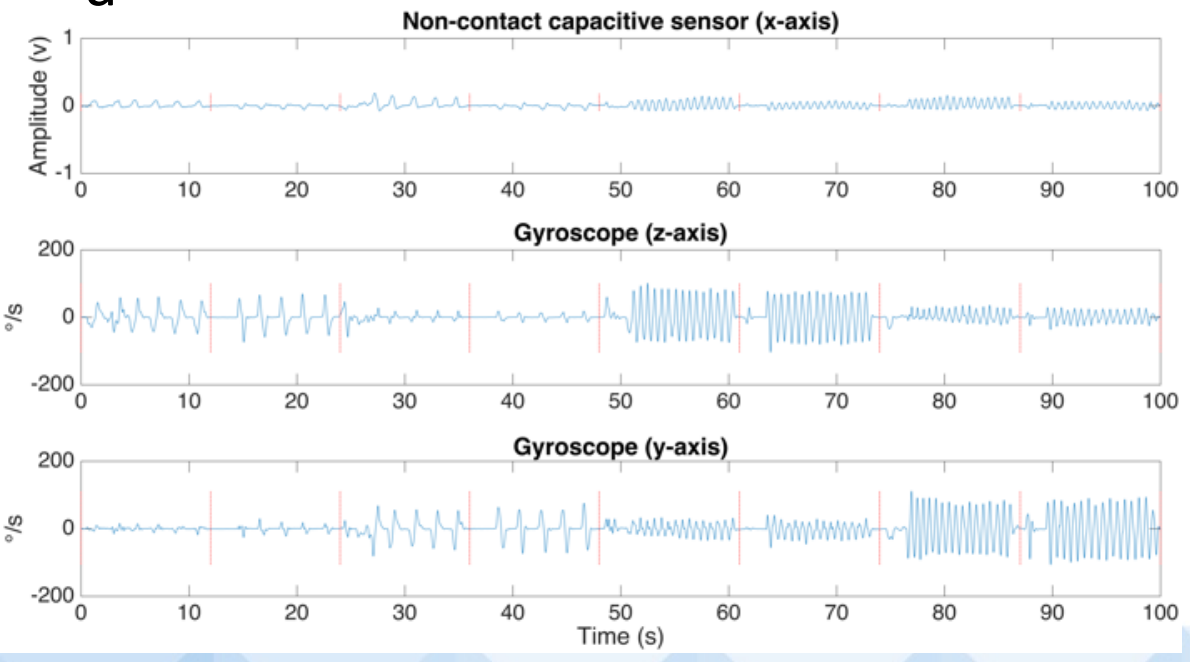

Healthy subject
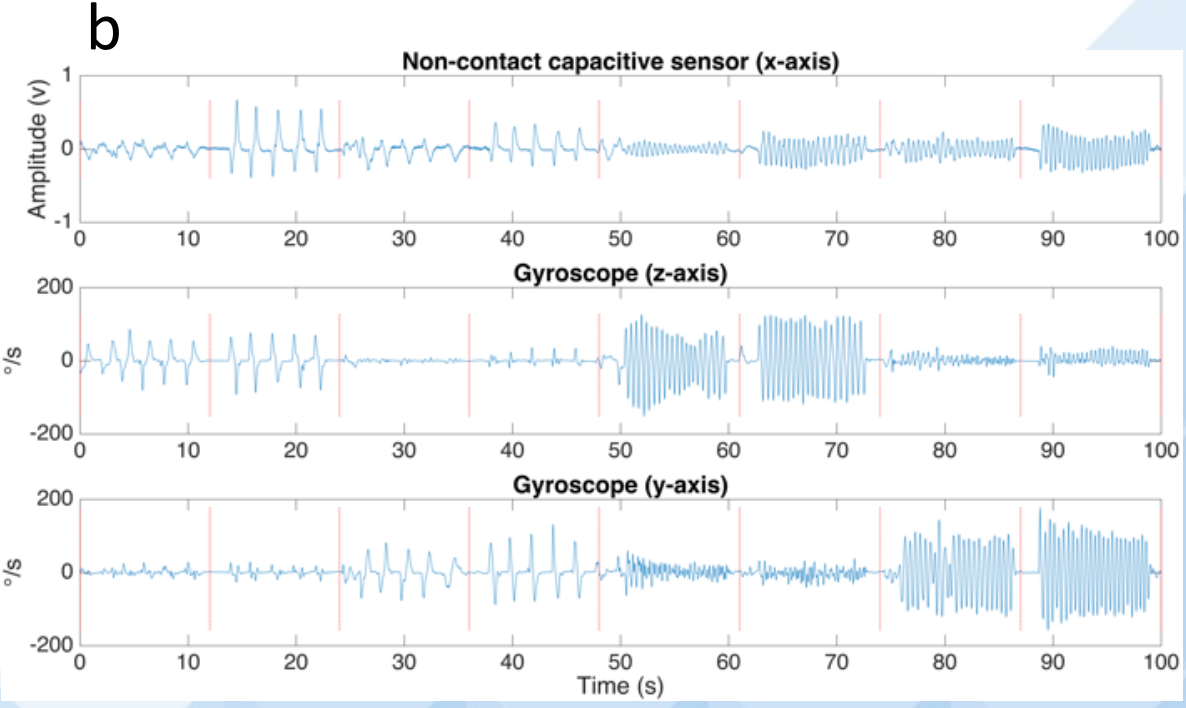

Subject with Parkinson's disease 
World Congress on Medical Physics eering

$-7-2=-\quad$ Task 1 (T1)

Task 1 (T1)

$5 x$
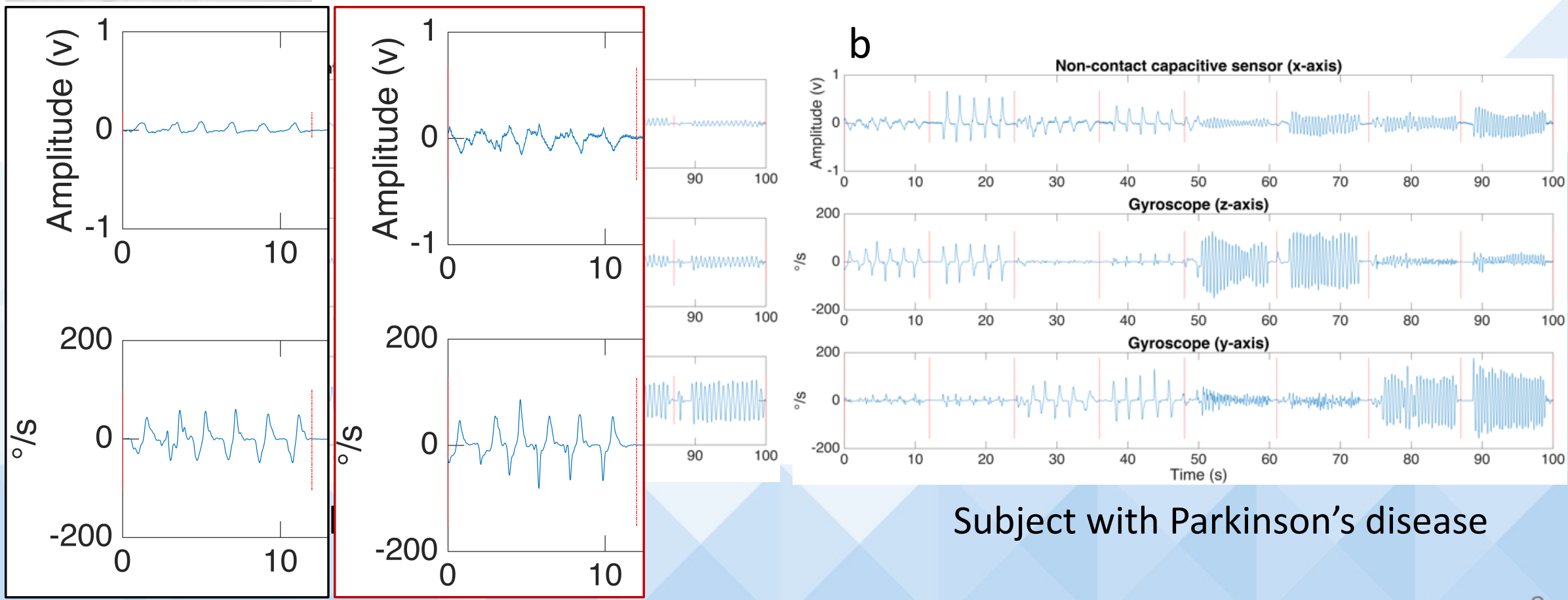

Subject with Parkinson's disease 
World Congress on Medical Physics

\& Biomedical Engineering

June 3-8, 2018, Prague, Cżech Republic, www.iupesm2018.org

\section{Results}

a
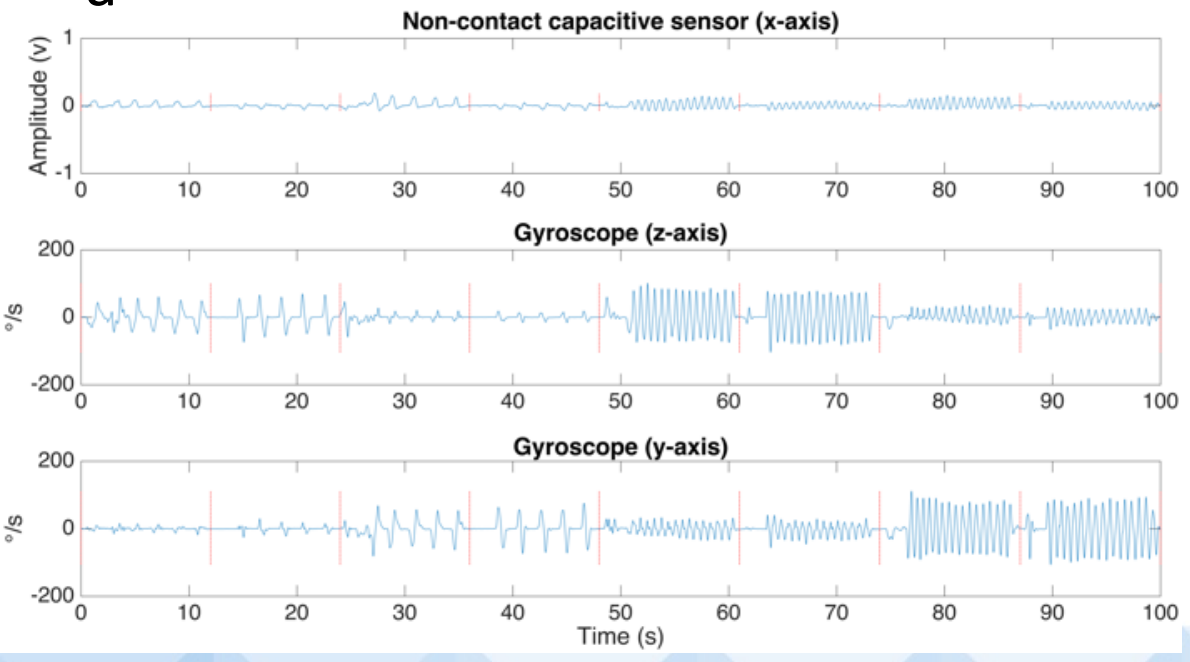

Healthy subject
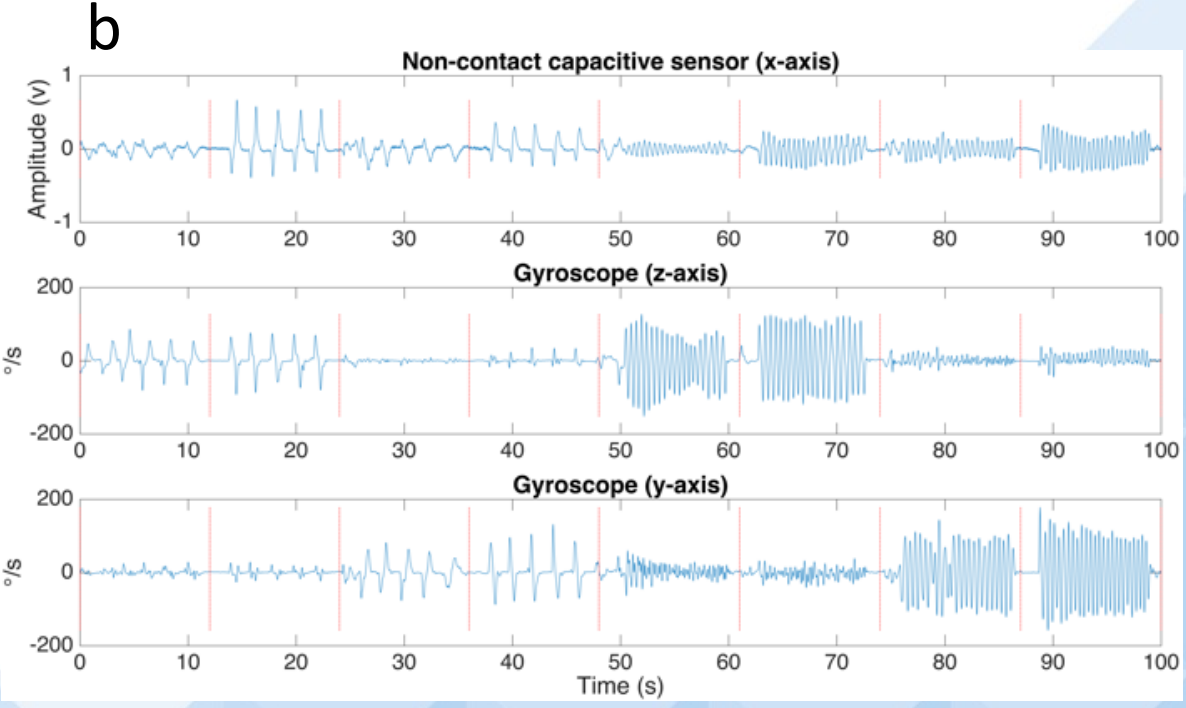

Subject with Parkinson's disease 
World Congress on Medical Physics

\& Biomedical Engin

Results

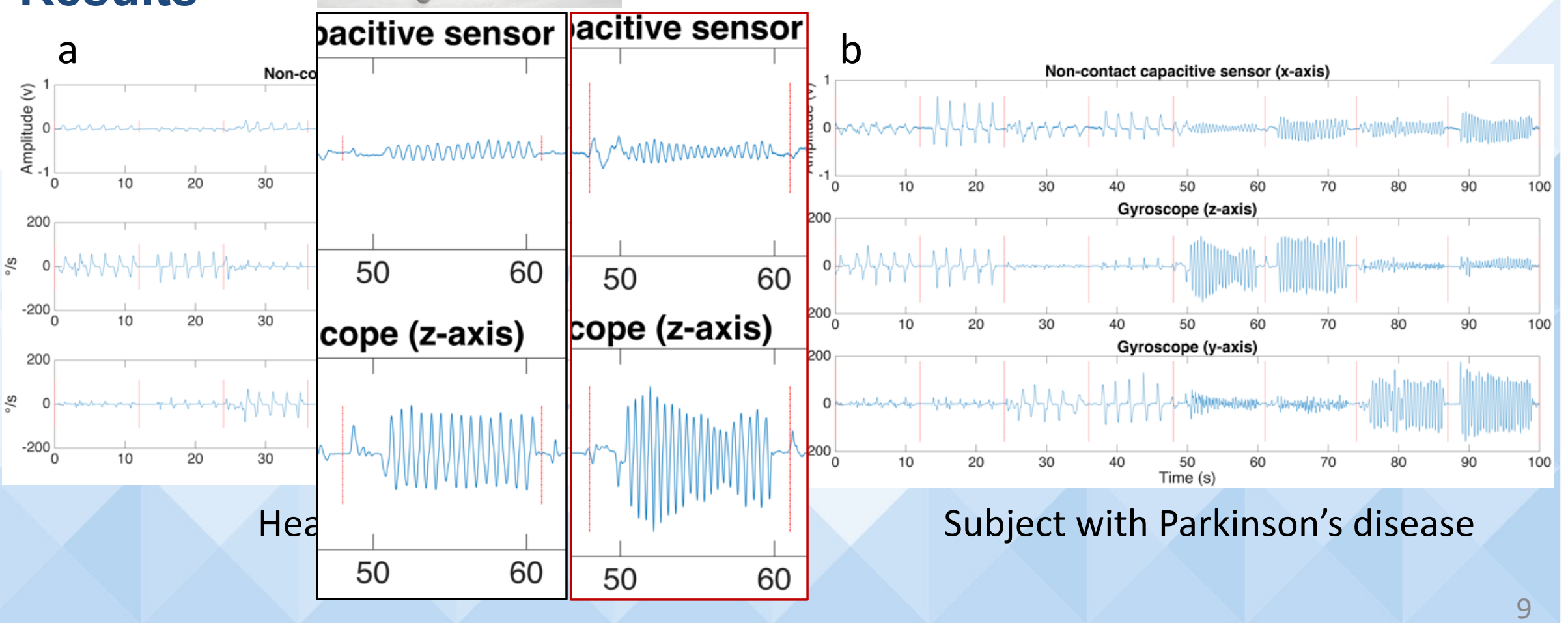

Task 1 (T1)

Radial deviation

$15 x$
IUPESM

PRAGUE 2018

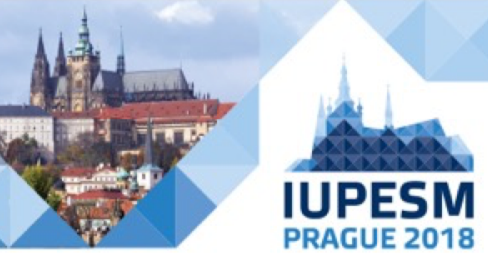


World Congress on Medical Physics

\& Biomedical Engineering

June 3-8, 2018, Prague, Czech Republic, www.iupesm2018.org

Results Time-dependent features

$\mathrm{H}=$ Healthy subject

$\mathrm{PD}=$ Subject with Parkinson's disease

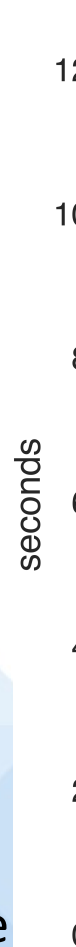

mpi ${ }_{\text {gyroz }}$

mpi ${ }_{\text {gyroY }}$

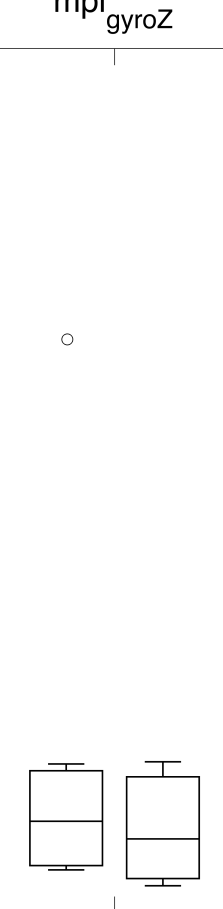

$\mathrm{H} \quad \mathrm{PD}$ tfl

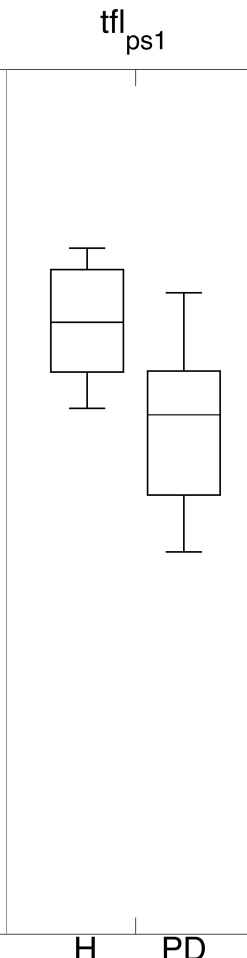

tfl gyroY

tfl $_{\text {gyroz }}$

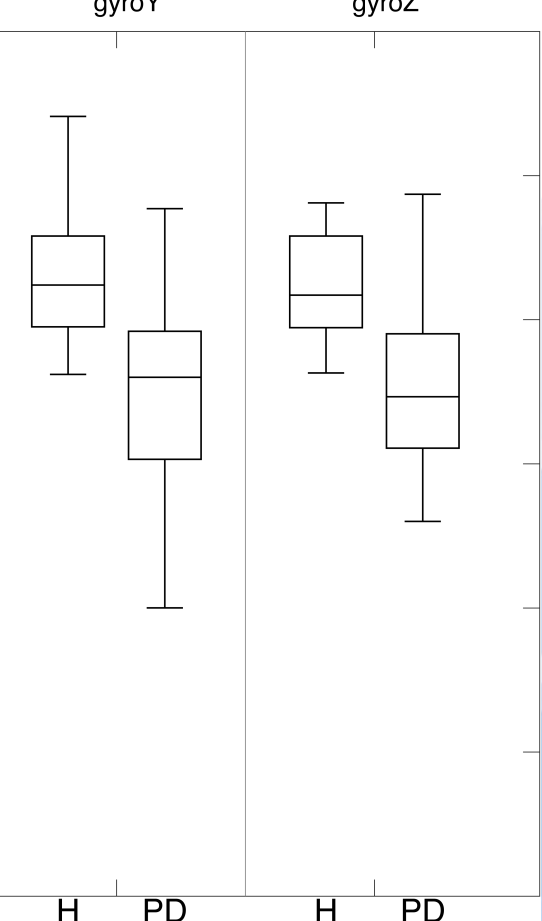


World Congress on Medical Physics

\& Biomedical Engineering

5 times

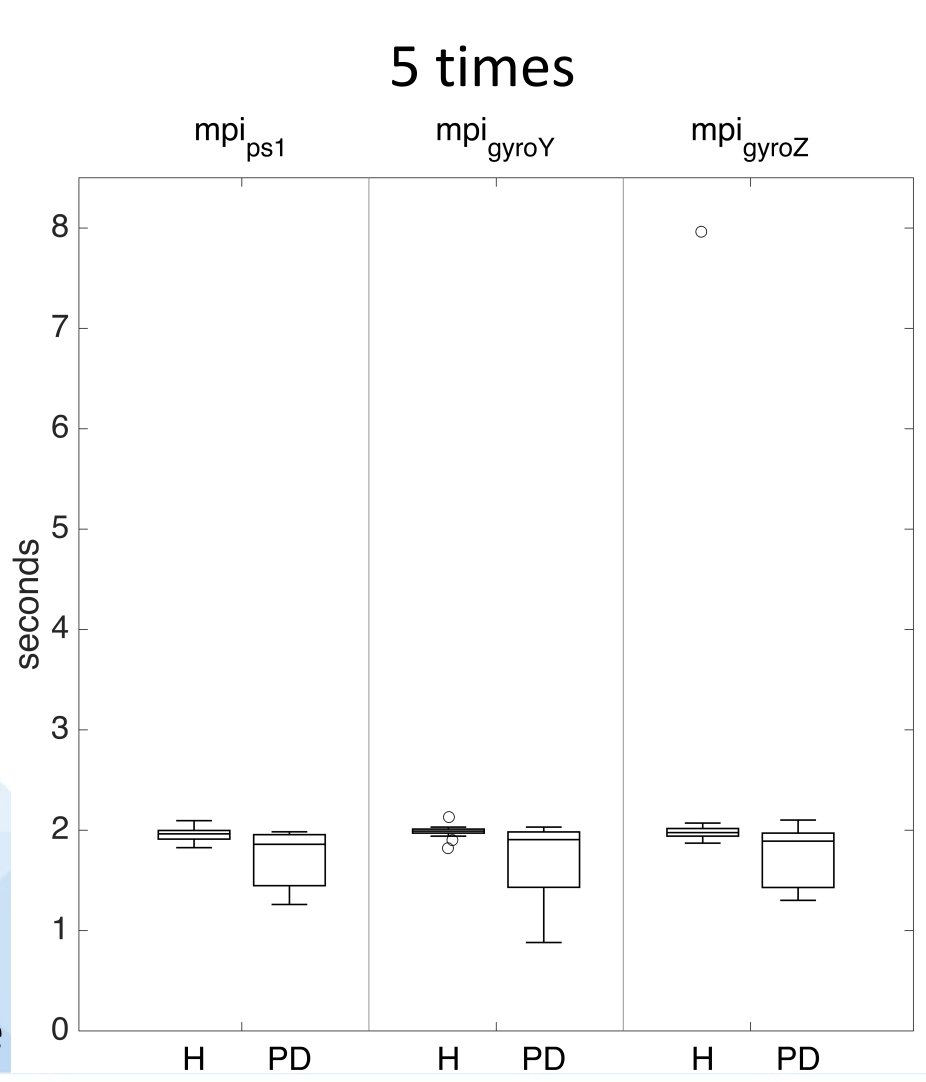

\section{Results}

$\mathrm{H}=$ Healthy subject

PD = Subject with Parkinson's disease

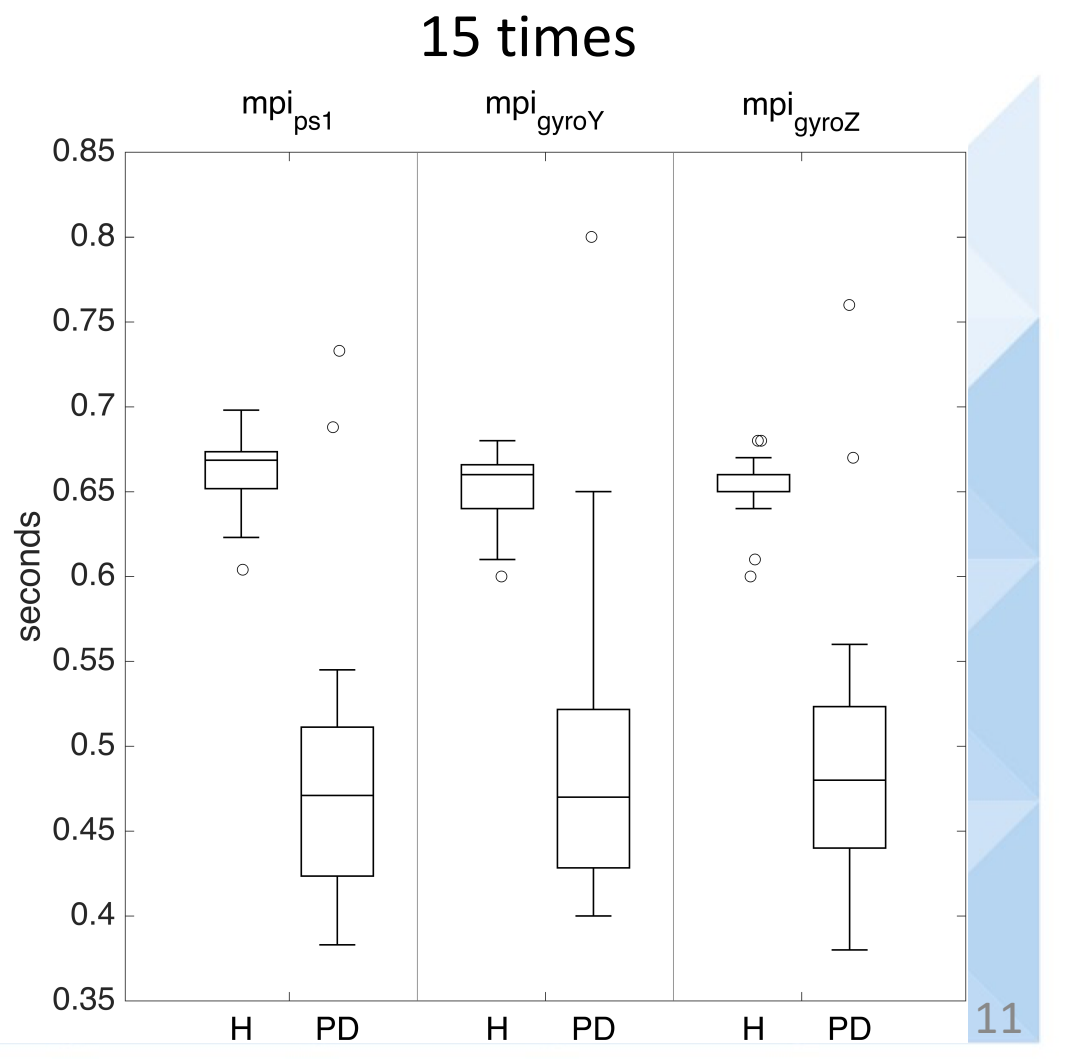




\section{Results}

\section{PCA}

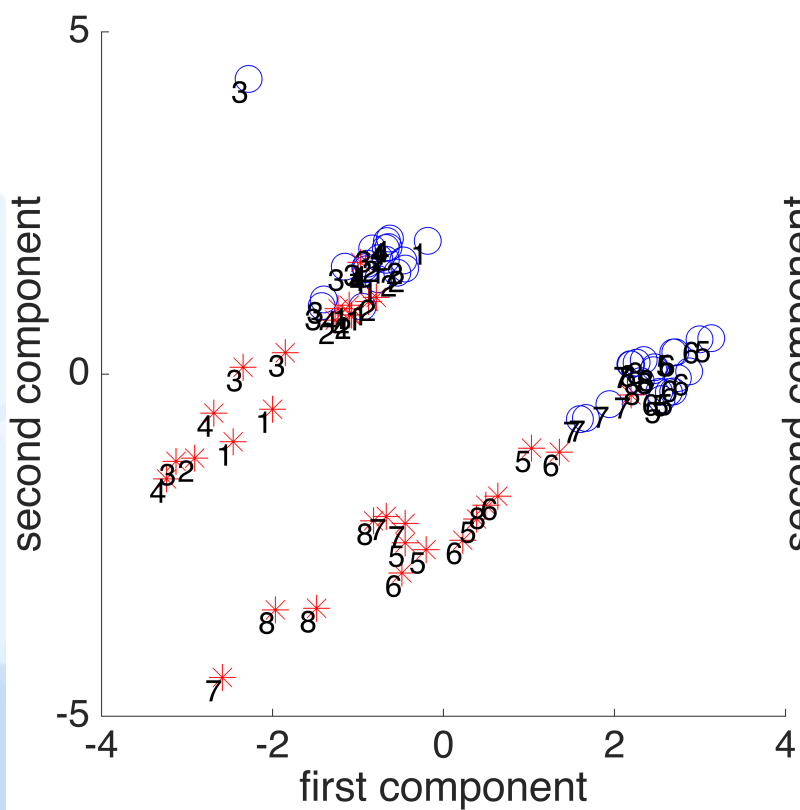

Sammon's Mapping

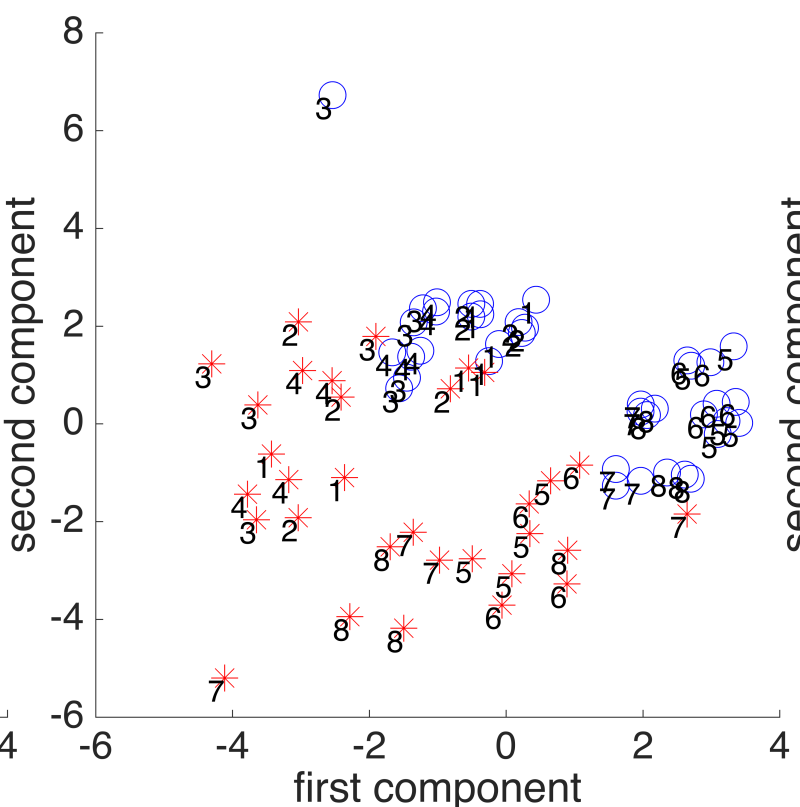

t-SNE

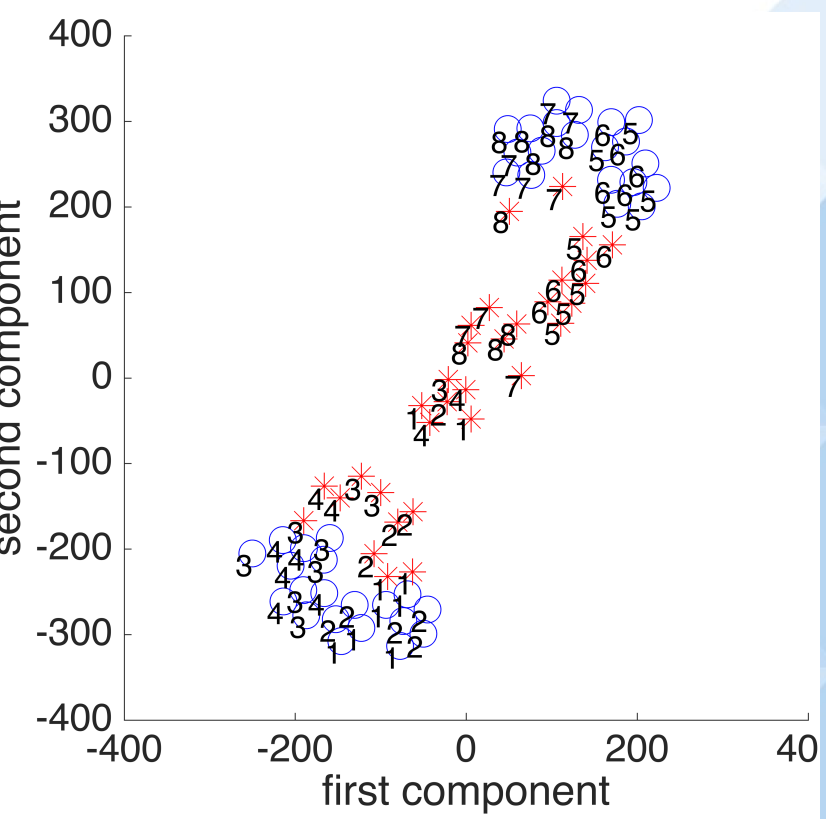

Blue $=$ Healthy subject $\quad$ Red $=$ Subject with Parkinson's disease 


\section{Conclusion}

- Non-contact capacitive sensors can be an alternative to measure hand movements

- This type of sensor could capture the differences among the movements performed by a healthy person from that with PD 


\section{Conclusion}

- Data projections showed that t-SNE was capable of grouping features considering the similarity of tasks and the condition of the person

- The number of subjects will be increased, so that all the methods can be further evaluated 


\section{Acknowledgements}

- The present work has the support of National Council for Scientific and Technological Development (CNPq), Coordination of Improvement of Higher Level Personnel (CAPES), Foundation for Research Support of the State of Minas Gerais (FAPEMIG - Project TEC - APQ-00942-17) and Foundation for Research Support of the Federal District (FAPDF - Grant number 00193.00000362/2018-81). A. O. Andrade is a fellow of CNPq, Brazil (305223 / 2014-3).
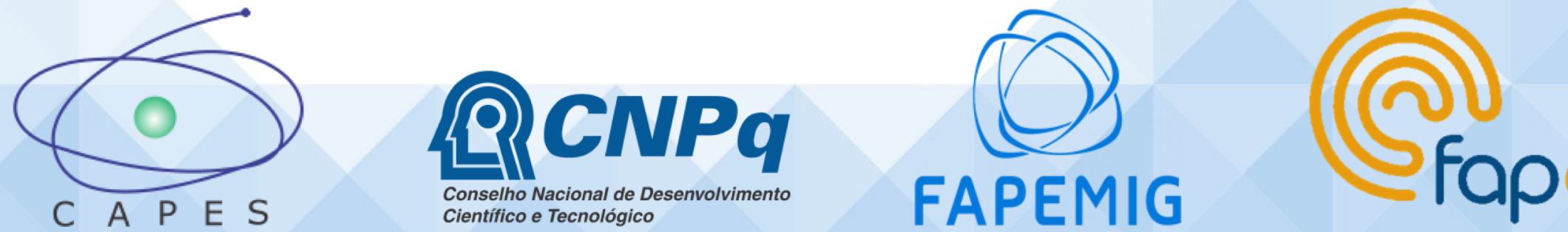
Abstract ID: 819

t-SNE applied to discriminate healthy individuals from those with Parkinson's disease executing motor tasks detected by non-contact capacitive sensors

Thank you very much!

Fábio Henrique M. Oliveira1,2 - oliveirafhm@gmail.com

Adriano O. Andrade ${ }^{1}$ - adriano@ufu.br

Thaíla Ferreira Zaruz ${ }^{1}$ - tzaruz@gmail.com

Marcus Fraga Vieira ${ }^{3}$ - marcus@ufg.br 